\title{
Leaf Discs as a Source Material for Plant Tissue Culture Studies of Sorghum bicolor (L.) Moench.
}

\author{
Sudhakararao POLA \\ Andhra University, A.U. College of Science and Technology, Department of Biotechnology, \\ Visakhapatnam, 530003, Andhra Pradesh, India; sudhakarpola@gmail.com
}

\begin{abstract}
Sorghum bicolor is one of the most difficult plant species to manipulate for tissue culture and genetic transformation; on the other hand Sorghum crop improvement through biotechnology requires efficient plant tissue culture protocols. In the present study a protocol has been optimized for Sorghum callus induction and regeneration from leaf tissue by optimizing the suitable explant, photoperiod and media composition. In Sorghum generally inflorescence tissue was used as explants for initiating callus cultures. Conversely, Sorghum flowering occurs only once in its life time and for few days only, thereby providing a small window of opportunity to provide source material or explant to initiate callus. Hence it is essential to identify a suitable explant, which can be available at any season. In the present study efficient callus induction was achieved on media supplemented in combination with $2 \mathrm{mgl}^{-1} 2,4,5-\mathrm{T}$ plus $1 \mathrm{mgl}^{-1} \mathrm{NAA}^{-1}$ and 0.5 $\mathrm{mgl}^{-1} \mathrm{ZN}$. Among the different combinations and concentrations of plant growth regulators tried for regeneration, $2.5 \mathrm{mgl}^{-1} \mathrm{TDZ} \mathrm{plus}^{-}$ $1.0 \mathrm{mgl}^{-1} \mathrm{BAP}$ and $0.5 \mathrm{mgl}^{-1} \mathrm{IAA}$ showed better shoot regeneration frequency with $62.2 \pm 4.6$ shoots per explant after 4 weeks of culture. Similarly, root induction was obtained from shoots with $1.0 \mathrm{mgl}^{-1} \mathrm{NAA}$ followed by their transfer to half strength MS medium which produced an average of two roots per shoot. Among the six genotypes tested, genotype 'IS3566 displayed superior results. Because of the reproducibility and the easy of accessibility of leaf tissue, the plant regeneration from leaf tissue provides a foundation for genetic transformation of Sorghum; this is of significant importance for improving important traits such as biomass, protein and sucrose content.
\end{abstract}

Keywords: callus differentiation, in vitro culture, genetic engineering, plantlet regeneration, plant growth regulators, transformation

Abbreviations: 2,4,5-T: trichlorophenoxy acetic acid; 2,4-D: 2,4-dichlorophenoxyacetic acid; IAA: indole-3-acetic acid; NAA: -naphthaleneacetic acid; TDZ: thidiazuron; ZN: zeatin; BAP: benzylaminopurine; KN: kinetin

\section{Introduction}

Sorghum (Sorghum bicolor) is an important cereal crop grown in the semi-arid tropics of Africa and Asia due to its drought tolerance capability. It is well adapted to a wide range of soil types and environmental conditions. Sorghum grain is used as a staple food in many countries and it contains reasonable amounts of protein and carbohydrate (Samia et al., 2005). Sorghum has a great potential both on the domestic and international markets due to its increasing demand for the production of food and feed products, alcoholic and non-alcoholic beverages (FAO, 2010). The nutrient composition of Sorghum is comparable to rice and wheat. Mineral matter, crude fibre, calcium, phosphorous and protein content are specifically higher in Sorghum than in rice (Indra and Krishnaveni, 2009). Consequently, the intention of improvement of the functional properties of Sorghum is essential (Mohamed et al., 2010).

Genetic engineering of Sorghum has emerged as an alternative tool for conventional breeding for the introduction of desirable traits into elite varieties. The routine use of plant tissue cultures for Sorghum transformation necessitates optimization of protocols for culture initiation and maintenance. However, Arun et al. (2010) and Indra and Krishnaveni (2009) reported that, Sorghum has been categorized as one of the most difficult plant species to manipulate for tissue culture and transformation.

Although, tissue culture from Sorghum was reported previously (Indra and Krishnaveni 2009; Nguyen et al., 2007; Pola et al., 2007; 2008; 2009). In many Sorghum tissue culture studies, inflorescence tissue was used as explants for initiating embryogenic cultures (Gupta et al., 2006; Jogeswar et al., 2007; Mani and Pola, 2003). Conversely, Sorghum flowering occurs only once in its life time and for few days only, thereby providing a small window of opportunity to initiate embryogenic cultures. This makes it essential to identify the correct developmental stage of explants to optimize Sorghum tissue culture.

In this direction, objectives of this study were to establish a simple and efficient plant regeneration system from leaf tissue, which can be used as source material for in vitro culture of Sorghum in any season. 


\section{Materials and methods}

Source material for in vitro culture

Sorghum bicolor genotypes, 'IS3566', 'SPV475', 'CSV13', 'CSV15', 'CSV112' and 'IS348' were obtained from NRCS, and ICRISAT, Hyderabad, India. Leaf discs from in-vitro raised seedlings were used as source material/explant. For getting leaf explants, mature seeds were surface sterilized with 5\% sodium hypochlorite for 4 to 5 minutes (field collected seeds contains many fungal spores, to remove this, we have to use high concentrated sodium hypochlorite for 4 to 5 minutes), rinsed three times with sterile distilled water, and inoculated on Petri dishes / test tubes containing $30 \mathrm{ml}$ of MS (Murashige and Skoog, 1962) medium. Each Petri dish was inoculated with five seeds. Seedlings were allowed to grow under a daily schedule of $16 \mathrm{~h}$ light and $8 \mathrm{~h}$ dark. After germination of the plantlets leaf discs were collected and transferred to test tubes $(150 \mathrm{~mm} \times 25 \mathrm{~mm})$ containing $10 \mathrm{ml}$ of the culture medium as described below. Light was provided by fluorescent lamps (Philips, TL40W/54) at an irradiance of $5.27 \mathrm{Wm} 2$ and temperature maintained at $25 \pm 2^{\circ} \mathrm{C}$ and $23 \pm 2^{\circ} \mathrm{C}$ during light and dark phase, respectively (Pola and Mani, 2006).

\section{Experimental design}

Data represents the mean of 3 independent experiments, each consisting of 25 explants. For each genotype a completely randomized design with 3 replications (25 explants per replication) was constructed to collect data on the frequency of embryogenic callus, callus fresh, dry weights, number of shoots, shoot length, roots obtained and other parameters.

\section{Media composition}

The basal medium formulation was MS medium supplemented with $300 \mathrm{mgl}^{-1}$ proline, glutamine, asparagine, $30 \mathrm{gl}^{-1}$ sucrose, $9 \mathrm{gl}^{-1}$ bacteriological grade agar. The callus induction medium was the basal MS medium supplemented with 1.0, 1.5, 2.0, $2.5 \mathrm{mgl}^{-1}$ concentrations of auxins as well as low concentrations of zeatin and kinetin. The differentiation/regeneration medium was the basal medium supplemented with $0.5,1.0,1.5,2.0$, and $2.5 \mathrm{mgl}^{-1} \mathrm{BAP}$, $\mathrm{KN}, \mathrm{TDZ}, \mathrm{ZN}$. The rooting medium was half strength basal MS medium supplemented with $20 \mathrm{gl}^{-1}$ sucrose, $0.8 \%$ bacteriological grade agar. All media were adjusted to $\mathrm{pH} 5.8$, and then autoclaved at $121^{\circ} \mathrm{C}$ for $20 \mathrm{~min}$. Filter sterilized plant growth regulators were added to the media after autoclaving.

\section{Callusing and regeneration}

From the 6 day old seedlings, 25 leaf discs were aseptically collected from the leaf. The leaf discs were placed on MS medium for callus formation with upper surface in contact with the callus induction medium. Inoculated sterile Petri dishes were incubated for one week at $25 \pm 2^{\circ} \mathrm{C}$ in continuous darkness, until the beginning of the embryogenesis, tissue remained on callus initiation medium, when embryogenic tissue found, and the calli were transferred to a callus maintenance and/or maturation medium. Subsequently the somatic embryos produced were transferred to regeneration medium.

\section{Frequency of embryogenic calli}

After 14 days of culture, frequency of embryogenic calli was calculated as the number of segments bearing regions of embryogenic callus and is expressed as percentage of the total number of explants inoculated. All cultures were transferred to fresh medium every 20 days except where changes were found necessary due to repeated release of phenolics or medium contamination. When embryogenic tissue found, the calli were transferred to a callus maintenance and/or maturation medium. Subsequently the somatic embryos were transferred to regeneration medium.

\section{Rooting}

Elongated, well developed individual regenerated shoots after attaining 3-6 cm length and each with two to four leaves were separated from the medium and used for root induction. The media used for root induction was half strength MS media supplemented with $1.0 \mathrm{mgl}^{-1}$ NAA. Culturing for rooting was also carried out in glass vessels under the same conditions as for shoot elongation. Well rooted shoots (ten plants for each genotype) were transferred into soil and kept in the greenhouse to check for normal development.

\section{Acclimatization of plantlets}

The plantlets, regenerated through various in vitro techniques in this study, were taken out from the culture medium and washed gently with double distilled water for removing all traces of medium from the roots. The washed plantlets were then transferred to small plastic cups containing sterile soil. The plastic cups were covered with sealed plastic vinyl bags to keep full humidity at $25 \pm 2^{\circ} \mathrm{C}$ in light conditions (photon flux density at $25 \mu \mathrm{mol} \mathrm{m}{ }^{-2}$ $\mathrm{S}-1,16 \mathrm{~h}$ ). The plantlets were moistened with water. As the plants grew vigorous, the bags were poked with chopsticks to allow air into the bags until the plants self supported. The polythene bags were removed after fifteen to twenty days. The plantlets were later transferred to larger pots containing sterile sand and soil (1:1 ratio) and kept under shade in the green house for another two weeks before transferring to field. Fully established regenerants were later established in the field for further growth.

\section{Results and discussion}

Explant sources, medium composition and genotypes are frequently used to be crucial factors in efficient callus induction as well as in plant regeneration (Rakshit et al., 2010). 
72


Fig. 1. In vitro plant regeneration from leaf explants of Sorghum bicolor

A. Leaf disc explants of Sorghum on callus induction medium; B. Developed callus on callus induction medium ; C. Development of somatic embryos on regeneration medium.; D. Shoot development in 'IS3566'; E. Shoot regeneration on MS + TDZ + BAP + IAA medium; F. Spontaneous development of shoots in genotype of 'IS3566'; G. Proliferation of multiple shoots on MS + TDZ + $\mathrm{BAP}+\mathrm{IAA}$ medium; H. Well developed plantlet in regeneration medium; I. Root initiation on MS + 1 mgl $^{-1} \mathrm{NAA}$; J. Regenerated shoots in the genotype of 'CSV15', 'IS348', 'CSV13', 'SPV475' 


\section{Leaf explants as a sources material for tissue culture}

It is universal that, immature embryos and meristematic tissues, having undifferentiated cells, are suitable for callus induction and plant regeneration than mature tissues (Morrish et al., 1987). In Sorghum also, immature embryos and immature inflorescence have been frequently used as explant sources for tissue culture and transformation (Gurel et al., 2009; Jogeswar et al., 2007). On the other hand, in Sorghum such explants are available only in a restricted period of the growth cycle and the explant availability is season dependent. This is in contrast to the ready availability of leaf explants because of abundant accessibility, ease of explant preparation, and short duration of callus induction, leaf explants were the most preferred source tissue/explant for tissue culture of Sorghum to optimize plant regeneration. Hence in the present study leaf explants were used as a sources material for tissue culture to conquer all the above problems.

Tab. 1. Effect of different plant growth regulators on callusing ability* $^{* *}$

\begin{tabular}{|c|c|c|}
\hline $\begin{array}{l}\text { Set. } \\
\text { no. }\end{array}$ & $\begin{array}{l}\text { Plant growth regulators and } \\
\text { its concentration in } \mathrm{mgl}^{-1}\end{array}$ & $\begin{array}{c}\text { Callusing } \\
\text { ability }\end{array}$ \\
\hline 1 & $1.0 \mathrm{mgl}^{-1} \mathrm{NAA}$ & -- \\
\hline 2 & $1.5 \mathrm{mgl}^{-1} \mathrm{NAA}$ & ++ \\
\hline 3 & $2.0 \mathrm{mgl}^{-1} \mathrm{NAA}$ & ++ \\
\hline 4 & $2.5 \mathrm{mgl}^{-1} \mathrm{NAA}$ & -- \\
\hline 5 & $1.0 \mathrm{mgl}^{-1} 2,4-\mathrm{D}$ & -- \\
\hline 6 & $1.5 \mathrm{mgl}^{-1} 2,4-\mathrm{D}$ & + \\
\hline 7 & $2.0 \mathrm{mgl}^{-1} 2,4-\mathrm{D}$ & + \\
\hline 8 & $2.5 \mathrm{mgl}^{-1} 2,4-\mathrm{D}$ & + \\
\hline 9 & $1.0 \mathrm{mgl}^{-1} 2,4,5-\mathrm{T}$ & + \\
\hline 10 & $1.5 \mathrm{mgl}^{-1} 2,4,5-\mathrm{T}$ & + \\
\hline 11 & $2.0 \mathrm{mgl}^{-1} 2,4,5-\mathrm{T}$ & +++ \\
\hline 12 & $2.5 \mathrm{mgl}^{-1} 2,4,5-\mathrm{T}$ & ++ \\
\hline 13 & $1.0 \mathrm{mgl}^{-1} 2,4,5-\mathrm{T}+0.5 \mathrm{mgl}^{-1} \mathrm{NAA}+0.5 \mathrm{mgl}^{-1} \mathrm{ZN}$ & ++ \\
\hline 14 & $1.5 \mathrm{mgl}^{-1} 2,4,5-\mathrm{T}+0.5 \mathrm{mgl}^{-1} \mathrm{NAA}+0.5 \mathrm{mgl}^{-1} \mathrm{ZN}$ & ++ \\
\hline 15 & $2.0 \mathrm{mgl}^{-1} 2,4,5-\mathrm{T}+0.5 \mathrm{mgl}^{-1} \mathrm{NAA}+0.5 \mathrm{mgl}^{-1} \mathrm{ZN}$ & +++ \\
\hline 16 & $2.5 \mathrm{mgl}^{-1} 2,4,5-\mathrm{T}+0.5 \mathrm{mgl}^{-1} \mathrm{NAA}+0.5 \mathrm{mgl}^{-1} \mathrm{ZN}$ & ++ \\
\hline 17 & $1.0 \mathrm{mgl}^{-1} 2,4,5-\mathrm{T}+1.0 \mathrm{mgl}^{-1} \mathrm{NAA}+0.5 \mathrm{mgl}^{-1} \mathrm{ZN}$ & +++ \\
\hline 18 & $1.5 \mathrm{mgl}^{-1} 2,4,5-\mathrm{T}+1.0 \mathrm{mgl}^{-1} \mathrm{NAA}+0.5 \mathrm{mgl}^{-1} \mathrm{ZN}$ & ++++ \\
\hline 19 & $2.0 \mathrm{mgl}^{-1} 2,4,5-\mathrm{T}+1.0 \mathrm{mgl}^{-1} \mathrm{NAA}+0.5 \mathrm{mgl}^{-1} \mathrm{ZN}$ & +++++ \\
\hline 20 & $2.0 \mathrm{mgl}^{-1} 2,4,5-\mathrm{T}+0.5 \mathrm{mgl}^{-1} \mathrm{NAA}+0.5 \mathrm{mgl}^{-1} \mathrm{KN}$ & ++ \\
\hline 21 & $2.0 \mathrm{mgl}^{-1} 2,4,5-\mathrm{T}+1.0 \mathrm{mgl}^{-1} \mathrm{NAA}+0.5 \mathrm{mgl}^{-1} \mathrm{KN}$ & ++ \\
\hline 22 & $2.0 \mathrm{mgl}^{-1} 2,4,5-\mathrm{T}+1.5 \mathrm{mgl}^{-1} \mathrm{NAA}+0.5 \mathrm{mgl}^{-1} \mathrm{KN}$ & ++++ \\
\hline 23 & $2.0 \mathrm{mgl}^{-1} 2,4,5-\mathrm{T}+2.0 \mathrm{mgl}^{-1} \mathrm{NAA}+0.5 \mathrm{mgl}^{-1} \mathrm{KN}$ & +++ \\
\hline 24 & $2.0 \mathrm{mgl}^{-1} 2,4,5-\mathrm{T}+2.5 \mathrm{mgl}^{-1} \mathrm{NAA}+0.5 \mathrm{mgl}^{-1} \mathrm{KN}$ & - \\
\hline
\end{tabular}

\section{Callus initiation}

Callus commencement is one of the noteworthy steps for selecting the suitability of genotype for tissue culture based research and for plant improvement program, pre- dominantly for genetic transformation. In the present study, various concentrations of auxin in combination with cytokinins were used. Among these, medium fortified with $2 \mathrm{mgl}^{-1} 2,4,5-\mathrm{T}$ plus $1 \mathrm{mgl}^{-1} \mathrm{NAA}$ and $0.5 \mathrm{mgl}^{-1}$ $\mathrm{ZN}$ was found to be promising to initiate callus.

Leaf disc explants (Fig. 1A) when cultured on callus induction medium resulted in two types of calli, namely, a non-embryogenic callus, usually friable, mucilage producing type which did not exhibit any differentiation, and the other a white, compact and nodular, embryogenic callus, which represents a source of a regenerable culture (Fig. 1C).

Both types of calli could be found to co-exist in a single explant, even though embryogenic portions bounded by or mixed with vacuolated, elongated, nonembryogenic callus clumps. The clumps were manually removed and embryogenic portions were subcultured (Fig. 1B) onto MS medium every three weeks. At each subculture, soft and non-embryogenic portions were removed and only embryogenic parts were screened for further cultures. After repeated selection and subculturing for two to three months, compact embryogenic calli were obtained from the primary callus. These calluses were used for further regeneration studies.

\section{Effect of media composition on cultures}

The role of plant growth regulators or hormones in cereal tissue culture is very important. In the present study, on plant growth regulator free medium the explants did not showed any morphological response up to three week. In contrast, explants cultured on $0.5,1.0,1.5,2.0$ and $2.5 \mathrm{mgl}^{-1}$ hormone concentrations in the medium exhibited callus formation in almost all cultures, however, some plant growth regulators promoted the callus induction and somatic embryo formation better than the others. Among the different auxins used in this experiment only $2.0 \mathrm{mgl}^{-1}$ 2,4,5-T and $2.0 \mathrm{mgl}^{-1} \mathrm{NAA}$ were able to produce high frequency of somatic embryos. However 2,4-D produced callus but the frequency was inadequate. In callus induction medium, when single auxin used in the medium, only restricted response was observed (Tab. 1), but combination of $2.0 \mathrm{mgl}^{-1} 2,4,5-\mathrm{T}$ with zeatin and kinetin at a concentrations of $0.5 \mathrm{mgl}^{-1}$ enhanced callus induction frequency. In my previous study with immature embryo explants (Pola et al., 2008), I have used different combinations and concentration of hormones, in that study single auxin used in the medium only $72 \%$ response was observed, but combination of 2,4,5-T with zeatin or kinetin, resulted the callus induction frequency increased upto $100 \%$, hence in this study I continued the 2,4,5-T and ZN combination. Despite the fact that, zeatin and kinetin are cytokinins, they also encourage callus initiation when these used in combination with 2,4,5-T and NAA. Previous reports in Sorghum also suggested 2,4-D to initiate callus; Indra and Krishnaveni (2009) obtained efficient callus response with $2 \mathrm{mgl}^{-1}$ 2,4-D in combination with $0.5 \mathrm{mgl}^{-1}$ kinetin. 
74

Tab. 2. Effect of various growth regulators in shoot multiplication from leaf explants of Sorghum bicolor ${ }^{*}$

\begin{tabular}{|c|c|c|c|c|c|c|}
\hline \multicolumn{5}{|c|}{ Concentration of PGR in $\mathrm{mgl}^{-1}$} & \multirow{2}{*}{$\begin{array}{c}\text { Shoot } \\
\text { number }\end{array}$} & \multirow{2}{*}{$\begin{array}{c}\begin{array}{c}\text { Root } \\
\text { number** }\end{array} \\
- \\
\end{array}$} \\
\hline TDZ & BAP & $\mathrm{ZN}$ & $\mathrm{KN}$ & IAA & & \\
\hline 0.5 & 0.5 & & & 0.5 & - & - \\
\hline 1.0 & 0.5 & & & 0.5 & $4.86 \pm 0.4$ & $8.9 \pm 0.2$ \\
\hline 1.5 & 0.5 & & & 0.5 & $9.84 \pm 0.1$ & $18.6 \pm 1.1$ \\
\hline 2.0 & 0.5 & & & 0.5 & $9.84 \pm 0.2$ & $12.7 \pm 2.6$ \\
\hline 2.5 & 0.5 & & & 0.5 & $14 \pm 0.6$ & $26.3 \pm 1.6$ \\
\hline 3.0 & 0.5 & & & 0.5 & $12.42 \pm 0.4$ & $28.9 \pm 3.4$ \\
\hline 0.5 & & 0.5 & & 0.5 & - & - \\
\hline 1.0 & & 0.5 & & 0.5 & - & - \\
\hline 1.5 & & 0.5 & & 0.5 & $4.8 \pm 0.8$ & $65.76 \pm 1.2$ \\
\hline 2.0 & & 0.5 & & 0.5 & $6.4 \pm 0.8$ & $79.43 \pm 4.8$ \\
\hline 2.5 & & 0.5 & & 0.5 & $8.26 \pm 0.2$ & $36.23 \pm 6.2$ \\
\hline 3.0 & & 0.5 & & 0.5 & - & - \\
\hline 0.5 & & & 0.5 & 0.5 & - & - \\
\hline 1.0 & & & 0.5 & 0.5 & $12.2 \pm 1.1$ & $26,8 \pm 2.2$ \\
\hline 1.5 & & & 0.5 & 0.5 & $14.2 \pm 1.4$ & $32.6 \pm 4.1$ \\
\hline 2.0 & & & 0.5 & 0.5 & $18.2 \pm 0.8$ & $41.6 \pm 2.8$ \\
\hline 2.5 & & & 0.5 & 0.5 & $26.23 \pm 1.9$ & $56.2 \pm 8.8$ \\
\hline 3.0 & & & 0.5 & 0.5 & $24.22 \pm 1.6$ & $54.2 \pm 6.4$ \\
\hline 0.5 & 1.0 & & & 0.5 & $28.4 \pm 2.1$ & $58.28 \pm 2.8$ \\
\hline 1.0 & 1.0 & & & 0.5 & $38.2 \pm 1.8$ & $62.94 \pm 8.6$ \\
\hline 1.5 & 1.0 & & & 0.5 & $46.2 \pm 2.6$ & $96.71 \pm 14.2$ \\
\hline 2.0 & 1.0 & & & 0.5 & $56.8 \pm 4.2$ & $118.0 \pm 12.2$ \\
\hline 2.5 & 1.0 & & & 0.5 & $62.2 \pm 4.6$ & $126.46 \pm 14.8$ \\
\hline 3.0 & 1.0 & & & 0.5 & $48.2 \pm 8.8$ & $106.67 \pm 16.2$ \\
\hline 0.5 & & 1.0 & & 0.5 & $32.54 \pm 1.8$ & $66.98 \pm 2.8$ \\
\hline 1.0 & & 1.0 & & 0.5 & $30.4 \pm 1.6$ & $62.2 \pm 6.4$ \\
\hline 1.5 & & 1.0 & & 0.5 & $36.12 \pm 2.1$ & $72.4 \pm .8 .8$ \\
\hline 2.0 & & 1.0 & & 0.5 & $35.54 \pm 4.2$ & $70.82 \pm 2.6$ \\
\hline 2.5 & & 1.0 & & 0.5 & $37.21 \pm 2.2$ & $76.83 \pm 4.8$ \\
\hline 3.0 & & 1.0 & & 0.5 & $37.15 \pm 0.6$ & $83.84 \pm 12.2$ \\
\hline 0.5 & & & 1.0 & 0.5 & $37.25 \pm 6.2$ & $89.4 \pm 8.4$ \\
\hline 1.0 & & & 1.0 & 0.5 & $30.14 \pm 4.8$ & $66.84 \pm 12.6$ \\
\hline 1.5 & & & 1.0 & 0.5 & $30.4 \pm 2.6$ & $62.9 \pm 8.2$ \\
\hline 2.0 & & & 1.0 & 0.5 & $26.45 \pm 1.8$ & $53.2 \pm 6.4$ \\
\hline 2.5 & & & 1.0 & 0.5 & $23.14 \pm 0.8$ & $67.9 \pm 8.2$ \\
\hline 3.0 & & & 1.0 & 0.5 & $34.64 \pm 2.2$ & $86.0 \pm 12.8$ \\
\hline 0.5 & 0.5 & 0.5 & 0.5 & 0.5 & - & - \\
\hline 1.0 & 1.0 & 1.0 & 1.0 & 0.5 & $38.6 \pm 1.1$ & $86.0 \pm 14.8$ \\
\hline 1.5 & 1.5 & 1.5 & 1.5 & 0.5 & $52.4 \pm 2.8$ & $108.9 \pm 8.6$ \\
\hline 2.0 & 2.0 & 2.0 & 2.0 & 0.5 & $24.67 \pm 2.2$ & $48.3 \pm 6.8$ \\
\hline 2.5 & 2.5 & 2.5 & 2.5 & 0.5 & $58.62 \pm 6.4$ & $122.82 \pm 8.2$ \\
\hline 3.0 & 3.0 & 3.0 & 3.0 & 0.5 & $20.50 \pm 2.8$ & $40.76 \pm 2.8$ \\
\hline 1.5 & 1.0 & 1.0 & 1.0 & 0.5 & $48.6 \pm 4.4$ & $79.43 \pm 12.8$ \\
\hline 2.0 & 1.0 & 1.0 & 1.0 & 0.5 & $56.10 \pm 6.6$ & $96.23 \pm 6.8$ \\
\hline 2.5 & 1.0 & 1.0 & 1.0 & 0.5 & $54.2 \pm 8.4$ & $118.95 \pm 12.2$ \\
\hline
\end{tabular}

${ }^{*}$ Each value represents the mean \pm SE of three repeated experiments each with 25 explants. ${ }^{* *}$ Rooting media: $1 \mathrm{mgl}^{-1} \mathrm{NAA}$

Zhang et al. (2010) also used this concentration to initiate callus from Sorghum. Studies in other poaceae plants also observed significant results with 2,4-D. Joshi et al. (2010) reported efficient callus in Zea mays with $5 \mathrm{mgl}^{-1}$ 2,4-D and $2 \mathrm{mgl}^{-1} \mathrm{NAA}+1 \mathrm{mgl}^{-1}$ BAP. Jason et al. (2009) used $5 \mathrm{mgl}^{-1}$ 2,4-D for callus initiation in Panicum virgatum. Misuk et al. (2008) reported efficient callus induction in Panicum maximum with $4.0 \mathrm{mgl}^{-1}$ 2,4-D.

\section{Regeneration}

After the embryogenic callus clumps were transferred to the shoot development medium (Fig. 1D), green shoots developed from somatic embryos (Fig. 1E). Spontaneous development of shoots (Fig. 1F) and plantlets from embryogenic callus was observed on cytokine medium only. Media free of BAP and TDZ or supplemented only with auxins were not effective for improved differentiation of shoots. For regeneration different concentrations $(0.5,1.0$, 1.5 and 2.0) and combination of BAP, TDZ, ZN, KN and IAA were used in the regeneration medium.

When medium fortified BAP or TDZ only, the plantlets ranged from 3-14 in a single culture, but combination of BAP, TDZ and IAA with addition of $1000 \mathrm{mgl}^{-1} \mathrm{~L}$ proline and $\mathrm{L}$-asparagine produced additional number of shoots (up to 62 shoots per culture ). Addition of BAP and TDZ with IAA at $0.5 \mathrm{mgl}^{-1}$ enhances multiple shoot formation. Here the combination of TDZ and BAP considerably stimulated the multiple shoot initiation in the presence of IAA (Fig. 1G). The number of shoots formed per each explant or the production efficiency of multiple shoots varied with the genotypes as well as different concentrations of cytokinins. Maximum number of multiple shoots were observed at $2.5 \mathrm{mgl}-1 \mathrm{TDZ}$ plus with 1.0 $\mathrm{mgl}^{-1}$ BAP $0.5 \mathrm{mgl}^{-1}$ of IAA (62.2 per culture in IS 3566) (Tab. 2). Shoot number was increased by means of steady increase of TDZ concentration from 0.5 to $2.5 \mathrm{mgl}^{-1}$ concentration in the regeneration medium, after $2.5 \mathrm{mgl}^{-1}$ the shoot number was decreased. The mean number of multiple shoots regenerated from leaf explants is given in the Tab. 2. Presence of TDZ, BAP and IAA in the regeneration medium has encouraging influence on plant regeneration. In embryogenesis, these combinations stimulate the production of axillary buds from the embryogenic callus that lead to the formation of multiple shoots (Fig. 1H). Combination of cytokinins with auxins also proved to be effective for multiple shoot formation in Sorghum. Previous studies by Sairam et al. (1999) reported 8 shoots per explant from mesophyll derived protoplasts of Sorghum using $0.2 \mathrm{mgl}^{-1} \mathrm{KN}+2 \mathrm{mgl}^{-1}$ BAP. Harshavardan et al. (2002) reported 35-40 shoot buds from the isolated shoot apices using MS $+5 \mu \mathrm{M}$ of TDZ $+17.72 \mu \mathrm{M} \mathrm{BAP}+1.074$ $\mu \mathrm{M}$ NAA. Nirwan and Kothari (2004) reported multiple shoot induction, using $2 \mathrm{mgl}^{-1} \mathrm{BAP}+0.5 \mathrm{mgl}^{-1}$ IAA. Baskaran et al. (2006) reported multiple shoot induction in Sorghum using $13.3 \mu \mathrm{M}$ BAP + 2,4-D 2.3 $\mu \mathrm{M}$. Kishore et al. (2006) reported multiple shoots by manipulation of $2.0 \mathrm{mgl}^{-1}$ BAP, $0.5 \mathrm{mgl}^{-1} 2.4-\mathrm{D}$ and $0.5 \mathrm{mgl}^{-1} \mathrm{TDZ}$. Misuk et al. (2008) reported regeneration with $1.0 \mathrm{mgl}^{-1}$ 
kinetin in Panicum maximum. Shyamkumar obtained efficient regeneration with MS media supplemented with $0.4 \mu \mathrm{M} 2,4-\mathrm{D}$ and $2.2 \mu \mathrm{M}$ BAP in centipede grass. Jason et al. (2009) reported efficient regeneration in Panicum virgatum with $5 \mu \mathrm{M}$ BAP alone in the medium. Joshi et al. (2010) reported efficient regeneration with $2 \mathrm{mgl}^{-1} \mathrm{BAP}$. $\mathrm{Xu}$ et al. (2009) $0.5 \mathrm{mg} \mathrm{l}^{-1} \mathrm{BA}$ and $1.0 \mathrm{mgl}^{-1}$ kinetin.

Efficient plant regeneration has been known as a major bottleneck on the successful application of genetic transformation of valuable genes into Sorghum genome. Previous studies in Sorghum by Visarada et al. (2003) reported 18.7 multiple shoots per explant, when shoot apex was cultured on $4.0 \mathrm{mgl}^{-1}$ BAP. Mishra and Khurana (2003) reported multiple shoot induction; they obtained 30

Tab. 3. Genotypic response of shoot regeneration**

\begin{tabular}{cc}
\hline Genotype & Average number of shoots per culture \\
\hline 'IS3566' & $62.2 \pm 4.6$ \\
'SPV475' & $60.1 \pm 3.2$ \\
'CSV13' & $58.6 \pm 2.1$ \\
'CSV112' & $36.64 \pm 2.4$ \\
'CSV15' & $15.2 \pm 1.6$ \\
'IS348' & $11.2 \pm 1.1$ \\
\hline
\end{tabular}

${ }^{* *}$ Each value represents the mean \pm SE of three repeated experiments each with 25 explants.

plantlets from a single explant in the genotype $296 \mathrm{~B}$, with $0.1 \mathrm{mgl}^{-1}$ BAP. Nirwan and Kothari (2004) reported 39 shoots per explant from mature embryo cultures and 48 shoots per explant from immature embryo cultures. Anju and Anandakumar (2005) reported 8.64 multiple shoots with $2 \mathrm{mgl}^{-1}$ BAP from shoot apex as a source explant. Baskaran et al. (2006) reported 35 shoots per callus in Sorghum. Whereas, in the present study 20-62 multiple shoots were obtained per single explant.

In monocotyledons species, several authors reported that TDZ induces multiple shoot formation. Shan et al. (2000) demonstrated that TDZ is capable of promoting callus regeneration and it has potential for enhancing the regeneration of cereal and grass species. Gupta and Conger (1998) observed in vitro differentiation of multiple shoot clumps from intact seedlings in switch grass when TDZ was used together with 2,4-D. Aparna and Rashid (2004) reported multiple shoots, with $10 \mu \mathrm{gl}^{-1} \mathrm{TDZ}$. In the present study also TDZ has been shown to induce multiple shoot formation from embryogenic callus. By means of these reports, use of TDZ and the level of cytokinins and combination with auxins used for plant regeneration appeared to be critical in producing multiple shoots in Sorghum. In the present study also, combination of $2.5 \mathrm{mgl}^{-1}$ of TDZ $1 \mathrm{mg} / \mathrm{l}$ BAP, with $0.5 \mathrm{mgl}^{-1}$ IAA bestow enhanced multiple shoot production.

Among the six genotypes studied in this study, leaf explants of 'IS3566' and 'SPV475' showed comparatively privileged culture response. The regeneration response of genotype 'IS3566' is $62.2 \pm 4.6$ shoots per culture, genotype 'SPV475' is $60.1 \pm 3.2$, and genotype 'CSV13' is $58.6 \pm 2.1$. Whereas, 'IS348' and 'CSV15' showed underprivileged response (Tab. 3).

Mirakabad et al. (2010) reported shoot regeneration rate is genotype dependent and genotype specificity affects regeneration and plant transformation rate; they also observed significant genotypic difference between callus wet and dry weights. Rakshit et al. (2010) observed genotypes play an important role in callusing and regeneration response in various crop plants. Lee et al. (2010) reported genotypic variation in callus induction, regeneration and transformation of ryegrass.

Consequently, identification of high quality callus with regard to its appearance, such as good-looking, healthy/no browning and actively growing, which is supposed to be embryogenic calli induced by some Sorghum genotypes, is one of the most essential factors for efficient plant regeneration. Jha et al. (2009) reported that, genotype had significant influence on callus induction frequency as well as regeneration; they also suggested that, development of high-frequency in vitro shoot organogenesis can help to overcome genotypic barriers.

In the present study also, Sorghum genotypes display a wide range in callus induction and regeneration capacity depending on their genetic background and their interaction with the culture media.

\section{Effect of photoperiod on cultures}

In the present study, results have revealed that dark/ light environment are also effective for callus induction and shoot regeneration. Darkness was normally observed to encourage more somatic embryogenesis than light conditions when auxin is presented in callus induction medium. Trials on the effect of $16 / 8 \mathrm{~h}$ (light/dark) photoperiod on calli induction and consequent shoot differentiation were undertaken in the present study. Results indicated that the quality of calli was enhanced, the frequencies of callus induction and subsequent differentiation were higher when callus was induced in total darkness rather than in a $16 / 8$ $\mathrm{h}$ photoperiod (Fig. 2). Phenolic secretions were observed, when callus cultures incubated under light.

In regeneration studies, this condition is absolutely upturned. In total darkness the regeneration frequency was deprived. When cultures incubated in $16 / 8 \mathrm{~h}$ (light/ dark) photoperiod $100 \%$ shoot regeneration response was observed. Bi et al. (2007) reported that many external factors affect plant growth and development but among them light is the most important because it regulates the whole process of growth and development.

Nhut et al. (2000) reported that, in organogenesis the sequence of dark or light affects the rate of differentiation into shoots, and is dependent on the length of exposure of callus culture to the dark. Light inhibited somatic embryogenic formation in plants such as barley (Kott and Kasha, 1984). The effect of light can be interpreted as acting on 
76

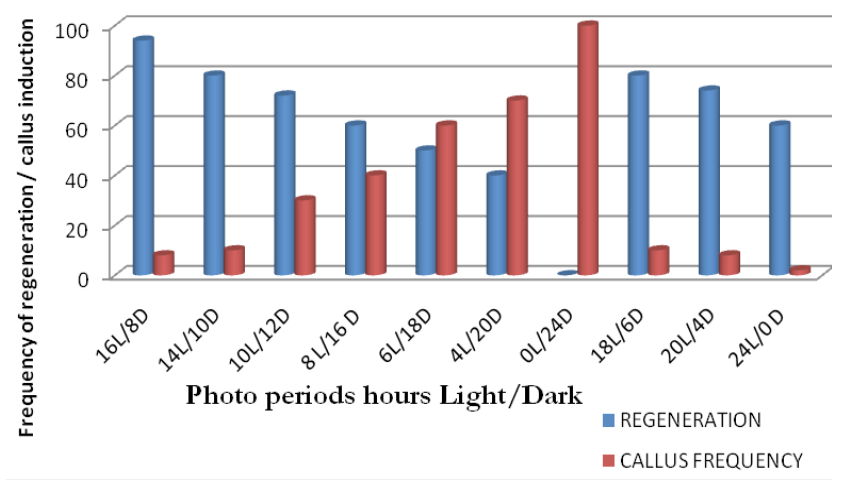

Fig. 2. Effect of photoperiod on cultures

metabolism and sugar uptake. Furthermore, light may act on energy dependent sugar uptake and metabolism (Nhut et al., 2000). Maheswari et al. (2006) reported that maintaining the cultures in the dark was also absolutely essential for retardation of shoot growth in the callus induction phase.

The present results are also agreed with these reports. In our earlier studies (Pola et al., 2007) with Sorghum immature embryo explants also exhibited this type of response. As a result, dark/light environment are significant factors for callus induction and regeneration response in Sorghum leaf explant culture.

\section{Rooting}

As soon as the plantlets attained $3 \mathrm{~cm}$ hight, they were transferred to the rooting medium containing $1.0 \mathrm{mgl}^{-1}$ NAA (Fig. 1I). For rooting, initially I have tested with different auxins (2,4-D, IAA, IBA and NAA) at different concentrations but I observed most excellent performance with $1.0 \mathrm{mgl}^{-1}$ NAA only. In addition low level of sucrose in the medium and $1 / 2$ strength MS medium was found to favourable for rooting. Shoots after transferring onto the rooting medium, root initiation started within 6 to 9 days and it was depended on shoot number.

A maximum of 126 roots were observed in IS 3566 (Tab. 2). Our previous reports in leaf culture (Pola et al., 2009) also supported NAA for rooting; other reports in Sorghum by Kishore et al. (2006), Maheswari et al. (2006) also supported that $1 \mathrm{mgl}^{-1}$ NAA is outstanding for rooting.

\section{Acclimatization of regenerants in the green house}

As soon as the regenerated plantlets accomplish well developed root system, were taken out from the culture medium and washed gently with double distil water for removing all traces of medium from the roots and acclimatized as mentioned in the materials and methods. After acclimatization, the plantlets were later transferred to larger plastic pots containing sterile soil and kept under shade in the green house for another two weeks before transferring to the field. Fully established regenerants were later established in the field for further growth.

\section{Conclusions}

In general, genetic improvements are believed to be difficult in graminaceous species due to their recalcitrance to in vitro manipulations (Alagarsamy et al., 2009, Ahmadabadi et al., 2007). Arun Kumar et al. (2010), Zhao et al. (2010), Indra and Krishnaveni (2009) have been categorized Sorghum, as one of the most difficult plant species to manipulate for tissue culture and transformation. However, a routine and efficient tissue culture procedure is a pre requisite for generating transgenic plants and other genetic engineering experiments (Indra and Krishnaveni 2009; Jha et al. 2009). Aiming this, in the present study an efficient plant regeneration system was developed in Sorghum bicolor. Thus, enhanced shoot regeneration in Sorghum, achieved by optimising suitable explant, media components and photoperiod.

\section{Acknowledgement}

I thank Prof. T. Ramana, Head of the Department, Department of Biotechnology, Andhra University, Visakhapatnam, India and Prof. N. Sarada Mani, Professor, Department of Botany, Andhra University for their support and encouragement.

\section{References}

Arun KP, Bhat BV, Balakrishna D, Seetharama N (2010). Genetic Transformation of Sorghum (Sorghum bicolor (L.) Moench.). Int J Biotechnol Biochem 6:45-53.

Ahmadabadi M, Stephanie R, Ralph B (2007). A leaf based regeneration and transformation system for maize (Zea mays L.). Transgenic Res 16:437-448.

Alagarsamy K, Shunmugiah T, Karutha P, Manikandan R (2009). High frequency plant regeneration from embryogenic callus of a popular indica rice (Oryza sativa L.). Physiol Mol Biol Plants15:371-375.

Anju V, Ananadakumar P (2005). In vitro plant regeneration from different explants of Sorghum bicolor (L.) Moench. Plant Cell Biotechnol Mol Biol 6:101-108.

Aparna G, Rashid A (2004). TDZ induced somatic embryogenesis in non responsive caryopses of rice using a short treatment with 2,4-D. Plant Cell Tissue Organ Cult 76:29-33.

Bi R, Kou MM, Chen LG, Mao SR, Wang HG (2007). Plant regeneration throughcallus initiation from mature embryo of Triticum. Plant Breed 126:9-12.

Baskaran P, Rajeswari BR, Jayabalan N (2006). Development of an in vitro regeneration system in Sorghum [Sorghum bicolor (L) Moench] Using Root Transverse Thin Cell Layers Tur J Bot 30:1-9.

FAO (Food and Agricultural Organization) (2010) FAOSTAT. http://faostat.fao.org/faostat.

Gupta S, Khanna VK, Rameshwar S, Garg GK (2006). Strategies 
for overcoming genotypic imitations of in vitro regeneration and determination of genetic components of ariability of plant regeneration traits in Sorghum. Plant Cell Tissue Organ Cult 86:379-388.

Gupta SD, Conger BV (1998). In vitro differentiation of multiple shoot clumps from intact seedlings of switch grass. In Vitro Cell Dev Biol Plant 34:196-202.

Gurel S, Ekrem G, Rajvinder K, Joshua W, Ling M, Han Q, Peggy GL (2009). Efficient reproducible Agrobacteriummediated transformation of Sorghum using heat treatment of immature embryos. Plant Cell Rep 28:429-444.

Indra AP, Krishnaveni S (2009). Effect of hormones, explants and genotypes in in-vitro culturing of Sorghum. J Biochem Tech 1:96-103.

Jason NB, David G, Mann J, Joyce BL, Stewart CN Jr (2009) An Improved Tissue Culture System for Embryogenic Callus Production and Plant Regeneration in Switchgrass (Panicum virgatum L.). Bioenerg Res 2:267-274.

Jha P, Yadav CB, Anjaiah V, Bhat V (2009). In vitro plant regeneration through somatic embryogenesis and direct shoot organogenesis in Pennisetum glaucum (L.) R. Br. In Vitro Cell Dev Biol Plant 45:145-154.

Jogeswar G, Ranadheer D, Anjaiah V, KaviKishor PB (2007). High frequency somatic embryogenesis and regeneration in different genotypes of Sorghum bicolor (L.) Moench from immature inflorescence explants. In Vitro Cell Dev Biol Plant 43:159-166.

Joshi R, Shuklal A, Kumar P (2010). Interactive effect of ga3 and polyamines on in vitro somatic embryogenesis from immature embryos in maize (Zea mays 1.). Maydica 55:111119.

Kott LS, Kasha KJ (1984). Initiation and morphological development of somatic embryoids from barley cell cultures. Can J Bot 62:1245-1249

Kishore SN, Visarada KBRS, Aravinda LY, Pashupatinath E, Rao SV, Seetharama N (2006). In vitro culture methods in Sorghum with shoot tips the explant Material. Plant Cell Rep 25:174-182.

Lee KW, Gi J, Choi K, Kim S, Hyung Y, Chung H, Hyung P, Young L, Sang L (2010). Genotypic variation of Agrobacterium-mediated transformation of Italian Ryegrass. E J Biotechnol 13:8-9.

Mohamed MA, Isam A, Mohamed A, Elfadil EB, Eay A (2010). Polymerization of Sorghum protein digests by transglutaminase-Changes in structure and functional properties. Agric Biol J N Am 1:47-55

Maheswari M, Jyothilakshmi N, Yadav SK, Varalaxmi Y, Vijayalakshmi A, Vanaja M, Venkateswarlu B (2006). Efficient plant regeneration from shoot apices of Sorghum. Biol. Plantarum 50:741-744.

Misuk S, Takahara M, Ebina M, Takamizo T (2008). Evaluation of tissue culture response from mature seeds of Panicum spp. Grassland Sci 54: 125-130.
Morrish F, Vasil V, Vasil IK (1987). Development Morphogenesis and genetic manipulation in tissue and cell cultures of the Gramineae. Advanced in Genetics 24:431-482.

Mani NS, Pola S (2003). Multiple shoot induction from immature inflorescence in Sorghum bicolor (L.). Moench. Cytologia 68:199-204.

Mirakabad ZH, Bagheri AR, Mehrjerdi MZ (2010). Efficient protocol for break impasses of regeneration via callus for 20 genotypes of chickpea. Int J Plant Prod 4:115-128.

Mishra A, Khurana P (2003). Genotype dependent somatic embryogenesis and regeneration from leaf base cultures of Sorghum bicolor. J Plant Biochem Biotechnol 12:53-56.

Murashige T, Skoog F (1962). A revised medium for rapid growth and bioassays with tobacco tissue cultures. Physol Plantarum 15:473-497.

Nirwan RS, Kothari SL (2004). High frequency shoot organogenesis in Sorghum bicolor (L.). Moench. J Plant Biochem Biotechnol 13:149-152.

Nhut DT, Bui VL, Tranvan KTT (2000). Somatic embryogenesis and direct shoot regeneration of rice (Oryza sativa L.). using thin cell layer culture of apical meristematic tissue. J Plant Physiol 157:559-565.

Nguyen V, Thu T, Claeys M, Angenon G (2007).Agrobacteriummediated transformation of Sorghum (Sorghum bicolor (L.). Moench). using an improved in vitro regeneration system. Plant Cell Tiss Organ Cult 91:155-164.

Pola S, Mani NS (2006). Somatic embryogenesis and plantlet regeneration in Sorghum bicolor (L.). Moench from leaf segments. J Cell Mol Biol 5:99-107.

Pola S, Mani NS, Ramana T (2007). Enhanced shoot regeneration in tissue culture studies of Sorghum bicolor. J Agri Technol 3:275-286.

Pola S, Mani NS, Ramana T (2008). Plant tissue culture studies in Sorghum bicolor: immature embryo explants as the source material. Int J Plant Prod 2:1-14.

Pola S, Mani NS, Ramana T (2009). Long Term Maintenance of Callus Cultures from Immature Embryo of Sorghum bicolour. World J Agri Sci 5:415-421.

Pola S, Mani NS, Ramana T (2009). Mature embryo as a source material for efficient regeneration response in Sorghum (Sorghum bicolor L. Moench.). Seed Sci J 26:93-104.

Rakshit S, Zerka R, Sekhar JC, Fatma T, Sain D (2010). Callus induction and whole plant regeneration in elite Indian maize (Zea mays L.) inbreds. Plant Cell Tiss Organ Cult. 100(1):31-37.

Samia MA, Elmaki HB, Idris WH, Babiker EE, Eltinay AH (2005). Proximate composition, antinutritional factors and mineral content availability of selected legumes and cereals grown in sudan. J Food Technol 3:522-515.

Sairam RV, Seetharama N, Devi PS, Verma A, Murty UR, Potrykus I (1999). Culture and regeneration of mesophyll derived protoplast of Sorghum [Sorghum bicolor(L.) Moench]. Plant Cell Rep 18:972-977. 
78

Shan X, Li D, Qu R (2000). Thidiazuron promotes in vitro regeneration of wheat and barley. In Vitro Cell Dev Biol Plant 36:207-210.

Shyamkumar B, Chung BY, Lee SS, An BC, Lee EM, Cho JY (2009). Development of an embryogenic callus induction method for centipede grass (Eremochloa ophiuroides Munro) and subsequent plant regeneration. In Vitro Cell Dev Biol Plant 45:155-161.

Visarada KBRS, SaiKishore N, Balakrishna D, Rao SV (2003). Transient gus expression studies in Sorghum to develop a simple protocol for Agrobacterium mediated genetic transformation. J Genet Breed 57:147-154.
Xu L, Najeeb U, Raziuddin R, Shen WQ, Shou JY, Tang GX, Zhou WJ (2009). Development of an efficient tissue culture protocol for callus formation and plant regeneration of wetland species Juncus effusus L. In Vitro Cell Dev Biol Plant 45:610-618.

Zhao L, Shujun L, Songquan S (2010). Optimization of callus induction and plant regeneration from germinating seeds of sweet Sorghum (Sorghum bicolor Moench). Afr J Biotechnol 9:2367-2374 